\title{
Using ensemble climate projections to assess probabilistic hydrological change in the Nordic region
}

\author{
F. Wetterhall ${ }^{1,2,3}$, L. P. Graham ${ }^{1}$, J. Andréasson ${ }^{1}$, J. Rosberg ${ }^{1}$, and W. Yang ${ }^{1}$ \\ ${ }^{1}$ Swedish Meteorological and Hydrological Institue, Norrköping, Sweden \\ ${ }^{2}$ Department of Geography, King's College London, UK \\ ${ }^{3}$ European Centre for Medium Range Weather Forecasting, Reading, UK
}

Received: 5 February 2010 - Revised: 16 May 2011 - Accepted: 1 June 2011 - Published: 23 August 2011

\begin{abstract}
Assessing hydrological effects of global climate change at local scales is important for evaluating future hazards to society. However, applying climate model projections to local impact models can be difficult as outcomes can vary considerably between different climate models, and including results from many models is demanding. This study combines multiple climate model outputs with hydrological impact modelling through the use of response surfaces. Response surfaces represent the sensitivity of the impact model to incremental changes in climate variables and show probabilies for reaching a priori determined thresholds. Response surfaces were calculated using the HBV hydrological model for three basins in Sweden. An ensemble of future climate projections was then superimposed onto each response surface, producing a probability estimate for exceeding the threshold being evaluated. Site specific impacts thresholds were used where applicable. Probabilistic trends for future change in hazards or potential can be shown and evaluated. It is particularly useful for visualising the range of probable outcomes from climate models and can easily be updated with new results as they are made available.
\end{abstract}

\section{Introduction}

Hydrological events, e.g. floods and droughts, are strongly coupled to weather and can cause great damage to society and even endanger human lives. Human induced climate change and resulting changes in future weather will lead to changes in the hydrological cycle. This field of research has recently received a lot of attention; Fowler et al. (2007) provide an overview. Numerous studies have been performed

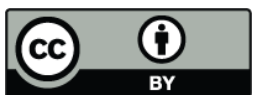

Correspondence to: F. Wetterhall (fredrik.wetterhall@ecmwf.int) and much discussion of uncertainties in assessing climate change impacts has ensued (e.g. Wilby and Harris, 2006; Wilby, 2010; Beven, 2011). Difficulties in assessing uncertainties are many, in particular regarding changes in extremes. Projections of future climate from global climate models (GCMs) have large uncertainties because of the inherent limitations in the climate models themselves, as well as in the emissions scenarios. Further uncertainties are introduced through regional downscaling and when additional models, such as hydrological models, are coupled to climate models to assess local impacts. The latter uncertainties originate both from parameter and model structure uncertainty in impact models, and uncertainty in the interface between the climate and impact models. How such uncertainties should be presented in a probabilistic manner to give stakeholders and decision-makers useful information about future risks is a challenging task. Although there is general recognition of a potentially large range in uncertainty from the climate models themselves, little has been done to assess this uncertainty in terms of probability. The information presented should both be quantitatively informative about possible future climate changes and describe uncertainties in the model systems.

There are two main approaches used in local impact modelling of climate change: top-down or bottom-up. The topdown approach is a more direct approach, where outputs of climate change projections are input into impact models and the effects of a climate change are evaluated a posteriori. This approach is computer intensive, since the complete future climate projections have to be simulated through the impact model. There is also often the need to correct for systematic errors in the climate model output, which adds to the computational processing burden (Déqué, 2007).

The bottom-up approach involves applying impact models to outputs from climate models by identifying thresholds a priori through a comprehensive sensitivity analysis and then

Published by Copernicus Publications on behalf of the European Geosciences Union. 
constructing response surfaces (Jones, 2001). This can be seen as a continuous delta change approach, which can be expanded to many dimensions depending on how many of the sensitive climate drivers are perturbed. Summary climate projection outputs are then superimposed onto the constructed response surface. Visualising more than three dimensions is difficult and the method is therefore most useful for two to three dimensions.

Both impact modelling approaches should ideally be conducted with several impact models as well as several climate models. In practice, however, most applications have been limited to the use of a single impact model. In a direct approach, likelihoods are given to each climate projection, thus creating a probabilistic future climate (Carter and Fronzek, 2005). In the response surface approach, probabilities are calculated according to the probability of climate projections falling above or below certain thresholds. Using specific thresholds can be useful in terms of communicating uncertainties and probabilities of a future climate change to decision and policy makers, since they can relate climate change impacts to specific events. Modelled probabilities can be related to real events by, for example, estimating the likelihood of hazards occurring more often in future projections.

The main objectives of this study were (1) to estimate the climate sensitivity of three catchments in Sweden using output from global and regional climate models to run the hydrological impact model HBV, and (2) to evaluate response surfaces based on the modelled runoff as a tool to visualise probabilistic scenarios of climate change.

\section{Methods and background}

\subsection{Basin description}

Lake Vänern and Lake Mälaren are the largest and third largest lakes in Sweden, respectively. Lake Vänern is also the largest lake in the European Union. Although these are natural lakes, man-made regulation at their outlets has been in operation since the 1940s. Lake Vänern is located in western Sweden and flows into the Göta River that has its outlet into the North Sea at Göteborg, Sweden's second largest city (Fig. 1). Lake Mälaren, located in eastern Sweden, flows into the Baltic Sea in the middle of Stockholm, the Swedish capital. Basic basin characteristics are shown in Table 1.

Lake Vänern has experienced extreme inflow and flooding conditions in recent years that affect the many communities located along its shores. This is compounded by sensitive geotechnical conditions in the downstream Göta River that dictates safe maximum lake outflow due to the risk of landslides. Lake Mälaren provides both water supply to the greater Stockholm area and shipping routes for inland communities located along its shores. As such, problems are associated with both high and low water levels. Potential problems at both lakes due to future climate change were

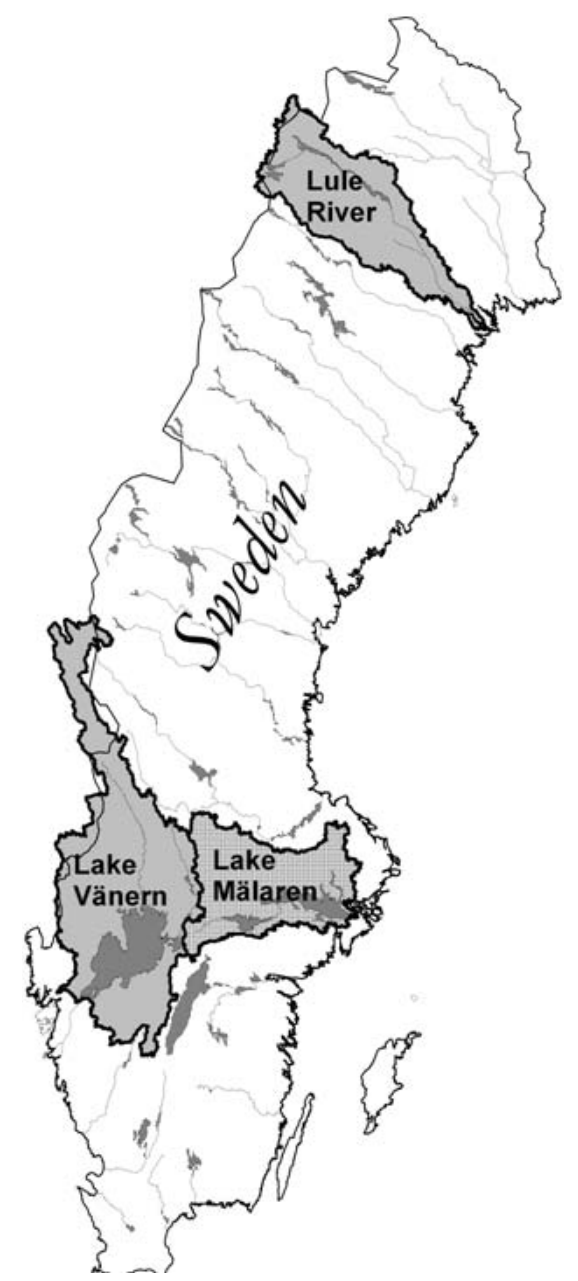

Fig. 1. The location of the study basins in Sweden.

identified by the Swedish Commission on Climate Change and Vulnerability (SOU 2007:60 Swedish Government Commission Report, 2007).

The Lule River is situated in northern Sweden and flows some $350 \mathrm{~km}$ southeast from the Scandinavian Mountains to Bothnian Bay in the Baltic Sea (Fig. 1). About $20 \%$ of the total hydropower produced in Sweden comes from the Lule River with its 15 hydropower stations. Cold region hydrology dictates the flow regime (Table 1), but previous studies have indicated a potential increase in hydropower production for this river with global warming over the coming century (Graham et al., 2007a).

\subsection{Hydrological modelling}

The HBV hydrological model was used as the impact model in the study. HBV is a conceptual semi-distributed rainfall runoff model that has a long history of applications worldwide (Lindström et al., 1997). It is widely used in the Nordic countries, both for operational and research purposes. Originally developed for operational runoff forecasting, it has 
Table 1. Basin characteristics of the study areas. The values in brackets are for the closest meteorological station. Mean values are for the period 1961-1990.

\begin{tabular}{lcccc}
\hline Catchment & $\begin{array}{c}\text { Basin } \\
\text { Area } \\
\left(\mathrm{km}^{2}\right)\end{array}$ & $\begin{array}{c}\text { Mean Annual } \\
\text { Temperature } \\
\left({ }^{\circ} \mathrm{C}\right)\end{array}$ & $\begin{array}{c}\text { Mean Annual } \\
\text { Precipitation } \\
\left(\mathrm{mm} \mathrm{yr}^{-1}\right)\end{array}$ & $\begin{array}{c}\text { Mean Annual } \\
\text { Runoff } \\
\left(\mathrm{m}^{3} \mathrm{~s}^{-1}\right)\end{array}$ \\
\hline Lake Vänern (Trollhättan) & 41230 & 6.8 & 788 & 530 \\
Lake Mälaren (Stockholm) & 22650 & 6.6 & 539 & 170 \\
Lule River (Jokkmokk) & 25240 & -1.4 & 509 & 490 \\
\hline
\end{tabular}

also been used extensively to perform impact studies for climate change assessments (Vehviläinen and Huttunen, 1997; Bergström et al., 2001; Andréasson et al., 2004), water quality (Arheimer and Brandt, 1998), and a combination of the two (Arheimer et al., 2005).

The model is usually operated on a daily timestep and includes routines for snow accumulation and melt, soil moisture accounting, groundwater response, and river routing. Input data include precipitation, $2 \mathrm{~m}$ temperature, and potential evapotranspiration. HBV is typically calibrated against river flow observations to obtain optimal performance in terms of both seasonal dynamics and runoff volume. Rating curves or regulation schemes for reservoirs and/or lakes can be included in the model to enable calculation of water levels. Use of these was made here for assessing impacts on water levels in both Lake Mälaren and Lake Vänern.

\subsection{Constructing response surfaces}

The framework of using probabilistic climate model output in combination with hydrological response surfaces consists of a number of steps, from creating scenarios of changes in the key climatic variables, through a sensitivity analysis of climate change and impact, identifying the critical thresholds and evaluating the probability exceedence of these thresholds, and consulting with stakeholders on adaptation options (Jones, 2001).

\subsubsection{Annual and seasonal changes}

The response surfaces in this study were generated by perturbing the observed input time series for the HBV model. The observed time series were calculated as sub-basin averages using an operational routine in use at SMHI for estimating areal input data (Johansson and Chen, 2003). The perturbation for temperature was constructed as an additive factor, varying from $0.5^{\circ} \mathrm{C}$ to $8^{\circ} \mathrm{C}$ with an increment of $0.5^{\circ} \mathrm{C}$, which was added to the observed temperature. The perturbation for precipitation was constructed as multiplicative factor, ranging from 0.8 to 1.6 with an increment of 0.05 . The perturbations of the observational series were carried out in two modes. Firstly, they were calculated as a uniform change regardless of season, hereafter referred to as annual perturbations (AP). The annual perturbed input series were calculated as:

$$
\begin{aligned}
& T(i)=T_{\mathrm{o}}(i)+X_{t} \\
& P(i)=P_{\mathrm{o}}(i) X_{p}
\end{aligned}
$$

where $T$ is temperature, $P$ precipitation, $X$ is the perturbation factor, and $i$ time (days).

However, intra-annual variability of both temperature and precipitation are important factors for hydrological regimes. Previous studies, e.g. the PRUDENCE Project (Christensen et al., 2007), have shown considerable monthly variation in projected climate changes, particularly in Northern Europe. For these reasons, it is not sufficient to look only at annual perturbations of temperature and precipitation. To account for seasonal differences in changes in temperature and precipitation, an estimate of seasonal distribution of future changes was calculated from PRUDENCE simulations applied to previous hydrological assessments (e.g. Graham et al., 2007b) and the more recent seasonal distributions from the 10000 simulations of the perturbed physics ensemble (Harris et al., 2010; see also Sect. 2.4.1). The seasonal pattern of change between the future period 2071-2100, compared to the control period 1961-1990, was used to create the a priori perturbations for input to the HBV Model, herafter referred to as seasonal perturbations (SP), according to Eqs. 3 and 4):

$$
\begin{aligned}
& T(i)=T_{\mathrm{o}}(i)+X_{t}\left(\bar{T}_{\mathrm{scen}}(j)-\bar{T}_{\mathrm{ctl}}(j)\right) \\
& P(i)=P_{\mathrm{o}}(i)\left(\frac{\bar{P}_{\mathrm{scen}}(j) \cdot X_{p}}{\bar{P}_{\mathrm{ctl}}(j)}\right)
\end{aligned}
$$

where $T$ is temperature, $P$ precipitation, $X$ is the perturbation factor, $i$ time (days), o observed values, $\bar{T}_{\text {scen }}$ future scenario projection of monthly mean temperature, $\bar{T}_{\text {ctl }}$ control period simulation of monthly mean temperature for $j$ month of the year (Similar denotations for mean monthly precipitation). The SP were normalised to have the same annual increment as the AP. The resulting perturbation factors are shown in Fig. 2. 

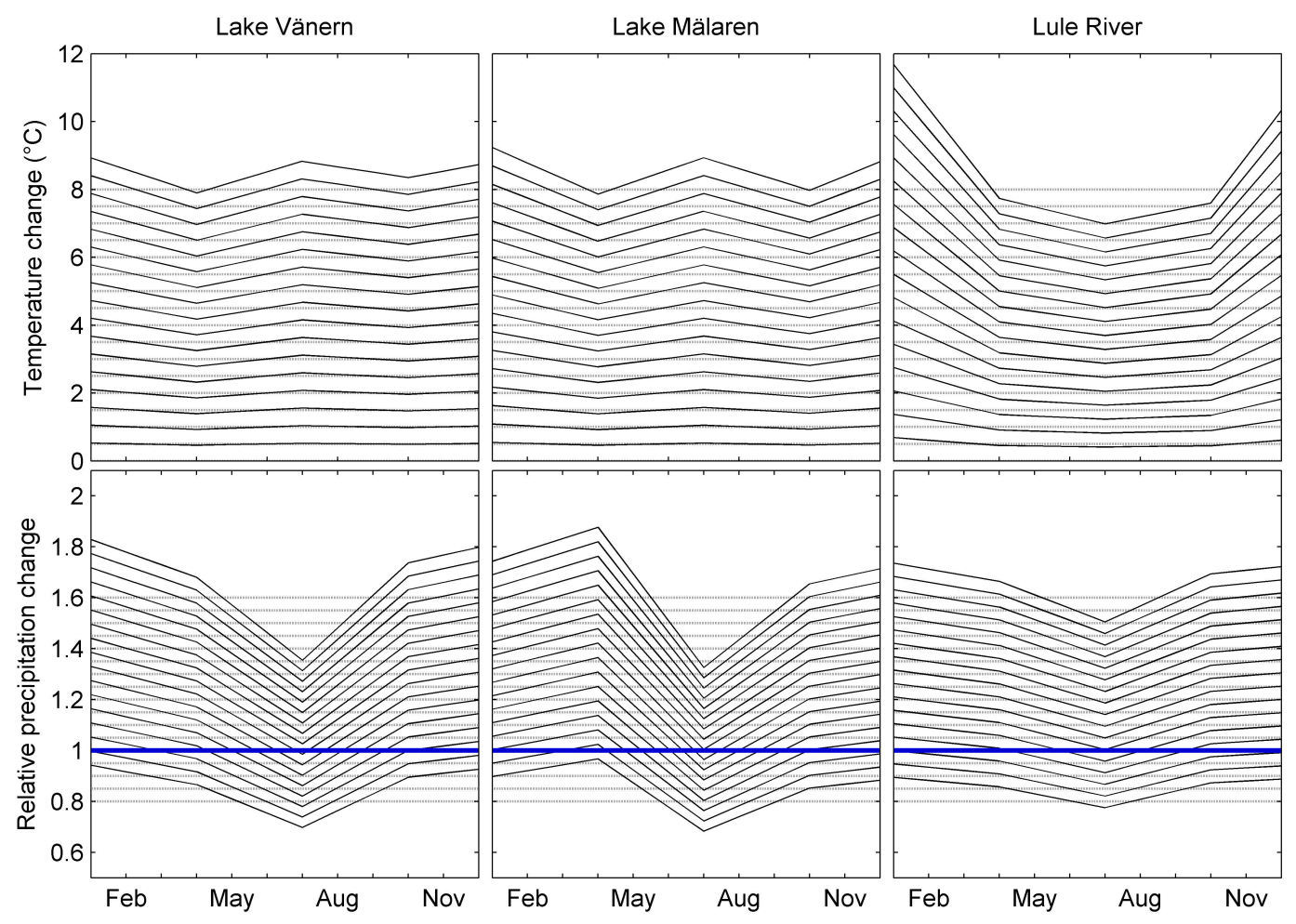

Fig. 2. Monthly change factors used to represent seasonal changes for temperature (top), and precipitation (bottom) for the Lake Vänern basin (left), Lake Mälaren (middle) and Lule river (right). Also shown are the corresponding constant annual change factors (horizontal lines).

\subsubsection{Selecting thresholds}

Critical thresholds for hydrological systems vary between basins. Although river discharge is generally the most important variable for consideration, temporal and spatial scales, and local topography play an important role. For Nordic conditions with its many lakes, water level can also be a critical factor. This is of particular consequence for the large natural lakes where outflows are nowadays regulated for optimal use of the water as a resource. The specifics of each hydrological basin must ideally be taken into account in resolving where critical thresholds lie. For all basins studied, response surfaces for change in mean annual river flow or inflow to lakes were created. In addition, response surfaces using specific thresholds were created as described below.

The relevant threshold for Lake Vänern was set to "100 consecutive days with outflow equal to or above $1000 \mathrm{~m}^{3} \mathrm{~s}^{-1}$ ". This very specific threshold corresponds to a particularly extreme situation that occurred during the winter of 2000-2001, causing extensive damage to surrounding communities. During this event there was also heightened risk for a dam break, which would have been catastrophic for the downstream Göta River. A second threshold was identified as the $100 \mathrm{yr}$ return period for the water level. A high water level in Lake Vänern can cause damage to the surrounding municipalities, whereas a too fast release of the water can lead to bank erosion and flooding of the downstream Göta river.

A threshold for Lake Mälaren was identified in terms of lake water level. This was set to "50 consecutive days with water levels equal to or below $4.15 \mathrm{~m}$ ". This height refers to a critical level in the local elevation reference system for Lake Mälaren where navigation becomes difficult, the intake of water for local water supply can be inhibited, and there is a higher risk for saltwater intrusion from the Baltic Sea. This level already occurs frequently in today's climate during the summer months, and it is of interest to assess if it may become even more frequent in the future.

Thresholds for the Lule River basin focused on changes in mean and seasonal river runoff, as a more specific threshold definition was not available. Since Lule River is regulated, a critical water level for a dam break would be a possibility. However, earlier studies have indicated a decrease in maximum flow because of increasing winter temperature and therefore an earlier and less severe spring flood. Seasonal changes were selected for presentation here as an example of a visualisation tool for dam managers. 


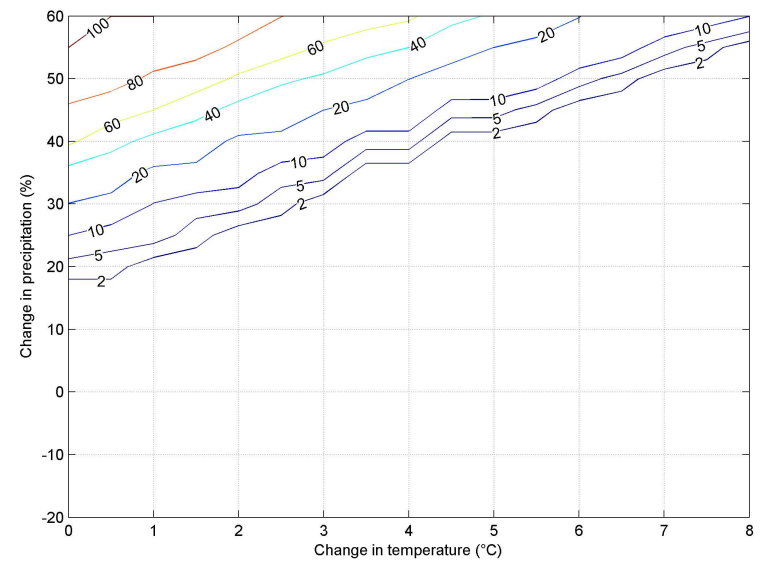

Fig. 3. Response surface for Lake Vänern. Threshold probability (\%) for reaching or exceeding 100 consecutive days with lake outflow equal to or above $1000 \mathrm{~m}^{3} \mathrm{~s}^{-1}$.

\subsubsection{Probability exceedance of thresholds}

Probability of exceeding a certain threshold was calculated as the frequency of exceedances of the perturbed physics ensemble that exceeded the certain thresholds. This probability should be considered as an estimated modelled probability and not as the true probability. The modelled probability was conditioned on the GCM used, in this case the HadCM3 model, and a different GCM with a different climate sensitivity might lead to a very different result.

\subsection{Climate model projections}

\subsubsection{Perturbed physics ensemble}

The response surfaces were used together with two different climate model outputs. Firstly, a joint probability distribution (JPD) of changes in precipitation and temperature in the future under the SRES-A1B emissions scenario was used (Harris et al., 2010). The distribution was created using a Bayesian approach, combining HadCM3 model output from transient climate simulations, as well as equilibrium climate simulations with a doubling of $\mathrm{CO}_{2}$ using a "perturbed physics" approach combined with an emulator to estimate the uncertainty in the model output. The distribution was constrained by observations and weights from other GCMs contained in the Coupled Model Intercomparison Project archive (CMIP3; IPCC, 2007), as well as regionalised simulations with the HadRM3 model over Europe. A set of 10000 paired samples of precipitation and temperature changes were drawn from the distributions. The grid points represent an area of approximately $300 \times 300 \mathrm{~km}$ and were given as seasonal and annual changes over 20-yr time slices from 2000-2100. Data was "winsorised", which means that the values below (above) the 1st (99th) percentile where set
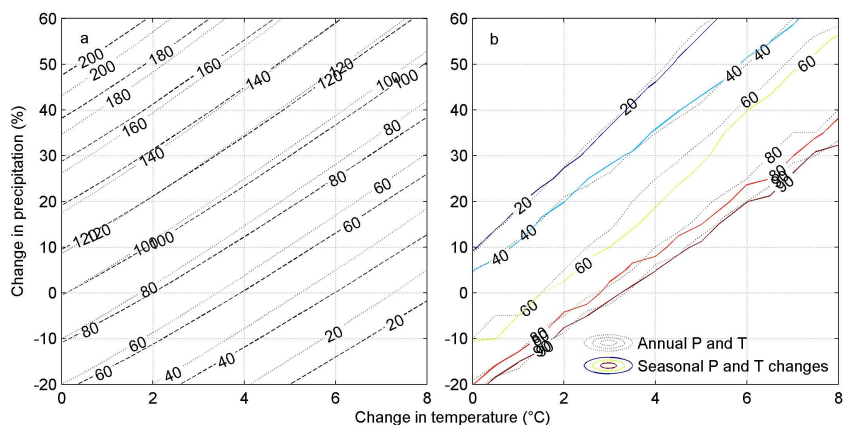

Fig. 4. Response surfaces for Lake Mälaren. (a) Mean annual runoff where the contours represent percent $(\%)$ of today's runoff (1961-1990). (b) Probability of occurrence (\%) for 50 consecutive days with low water threshold, $4.15 \mathrm{~m}$. Thin dotted lines show results using annual precipitation change and solid lines show results using seasonal precipitation change.

to the value of each percentile respectively. For a full description of the procedure we refer to Harris et al. (2010).

The 10000 paired sub-samples data can be seen as estimates of the underlying JPD and can be assumed to represent the true modelled probabilities. The data is more robust closer to the mean of the distribution, and the 5th and 95th percentiles can be seen as a measure of the spread of the model output. The JPD was displayed as contour plots in the response surfaces.

\subsubsection{RCM simulations}

Dynamically downscaled precipitation and temperature from 14 regional climate model (RCM) projections within the ENSEMBLES Project (van der Linden and Mitchell, 2009) were also used to drive direct simulations with the HBV Model (Olsson et al., 2011). This corresponds to the top down approach as described above. The RCMs used a horizontal grid resolution of $25-50 \mathrm{~km}$ and were driven by the SRES-A1B and A2 emissions scenario (Table 2). Even though dynamical downscaling improves the spatial and temporal properties of temperature and precipitation, biases are still prevalent and RCM outputs cannot be used directly in impact studies without some adjustment. Therefore, a systematic error correction was performed before feeding the projections into the HBV model (Yang et al., 2010). The method is a distributionbased scaling approach (DBS) where correction factors were identified by comparing single model output with the observations during the reference period and then applied to RCM simulation for future climate.

A joint probability distribution for precipitation and temperature was also estimated for the RCM runs using a bivariate Gaussian kernel density estimator, which is a nonparametric method of estimating the probability function of bivarate random variables (Botev et al., 2010). The resulting joint probability distribution was used to estimate the cumulative probabilities of exceeding thresholds (Figs. 9-10). Not 
Table 2. The RCMs included in this study. (Note that ECHAM5 refers to three different model runs using the same GCM.)

\begin{tabular}{|c|c|c|c|c|c|c|}
\hline Institution & Acronym & Resolution & Scenario & Driving GCM & Time period & Reference \\
\hline SMHI & RCA3 & $50 \mathrm{~km}$ & A1B & $\begin{array}{l}\text { ECHAM5-1 } \\
\text { ECHAM5-2 } \\
\text { ECHAM5-3 } \\
3 \text { CCSM3 } \\
\text { CNRM }\end{array}$ & $1991-2100$ & $\begin{array}{l}\text { Jones et al. (2004); } \\
\text { Kjellström et al. (2005) }\end{array}$ \\
\hline SMHI & RCA3 & $50 \mathrm{~km}$ & B1 & ECHAM5-1 & $1991-2100$ & \\
\hline SMHI & RCA3 & $25 \mathrm{~km}$ & A1B & ECHAM5-3 & $1991-2100$ & \\
\hline KNMI & RACMO2 & $25 \mathrm{~km}$ & A1B & ECHAM5-3 & $1991-2100$ & Meijgard et al. (2008) \\
\hline MPI & REMO & $25 \mathrm{~km}$ & A1B & ECHAM5-3 & $1991-2100$ & Jacob et al. (2001) \\
\hline CNRM & CNRM-RM4 & $25 \mathrm{~km}$ & A1B & ARPEGE & $1991-2050$ & Gibelin and Deque (2003) \\
\hline Met.no & HIRHAM & $25 \mathrm{~km}$ & & $\mathrm{BCM}$ & 1991-2050 & $\begin{array}{l}\text { Christensen et al. (1996); } \\
\text { Haugen and Haakenstad (2006) }\end{array}$ \\
\hline $\mathrm{C} 4 \mathrm{I}$ & RCA3 & $25 \mathrm{~km}$ & A1B & HadCM3-Q0 & 1991-2098 & \\
\hline $\mathrm{C} 4 \mathrm{I}$ & RCA3 & $25 \mathrm{~km}$ & $\mathrm{~A} 2$ & ECHAM5_3 & 1991-2050 & \\
\hline UKMetOffice (HC) & HadRM3 & $25 \mathrm{~km}$ & A1B & HadCM3_Q0 & 1991-2098 & Jones et al. (1995) \\
\hline
\end{tabular}

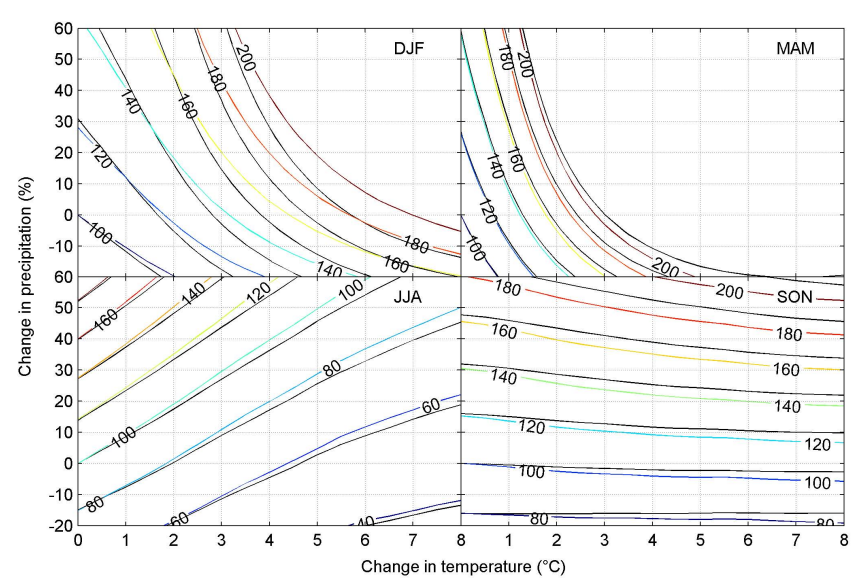

Fig. 5. Response surfaces for Lule River basin. Change in mean seasonal runoff where the contours represent percent $(\%)$ of today's runoff (1961-1990). Thin dotted lines show results using annual precipitation change and solid lines show results using seasonal precipitation change. Shown are DJF (December-JanuaryFebruary), MAM (March-April-May), JJA (June-July-August) and SON (September-October-November).

all methods were run up until the year 2100 (Table 2). Consequently, the numbers of RCMs in Figs. 6-10 vary depending on modelled time slice.

\subsection{Evaluating the response surfaces}

The response surfaces were evaluated seasonally, since the low water in Lake Mälaren occurs during the summer months, and the rain-based high flows in Lake Vänern occur during late autumn to early winter. Since preceding conditions are important for the water balance, the calculated changes in temperature and precipitation from the RCM and JPD simulations for Lake Mälaren were calculated as mean values for March-August, and then overlaid on the corresponding response surfaces. A similar approach was done with Lake Vänern but for September-February. Lake Vänern usually has its maximum inflow during spring flood, but this is projected to decrease in the future, accompanied by an increase in autumn and winter precipitation. All seasons were evaluated for the Lule River, since the runoff for this basin was predicted to shift seasonally.

\section{Results and discussion}

In general, increasing precipitation tends to increase runoff, while increasing temperature tends to dampen runoff due to a corresponding increase in evapotranspiration. The rate of runoff change is therefore highly dependent on the location of the watershed in relation to the current climate and how future climate is projected to change. Basin size and characteristics, such as lake surface area and volume, are also important. No analysis of the parameter uncertainty of the hydrological model coupled to the sensitivity surfaces was done in this study. 


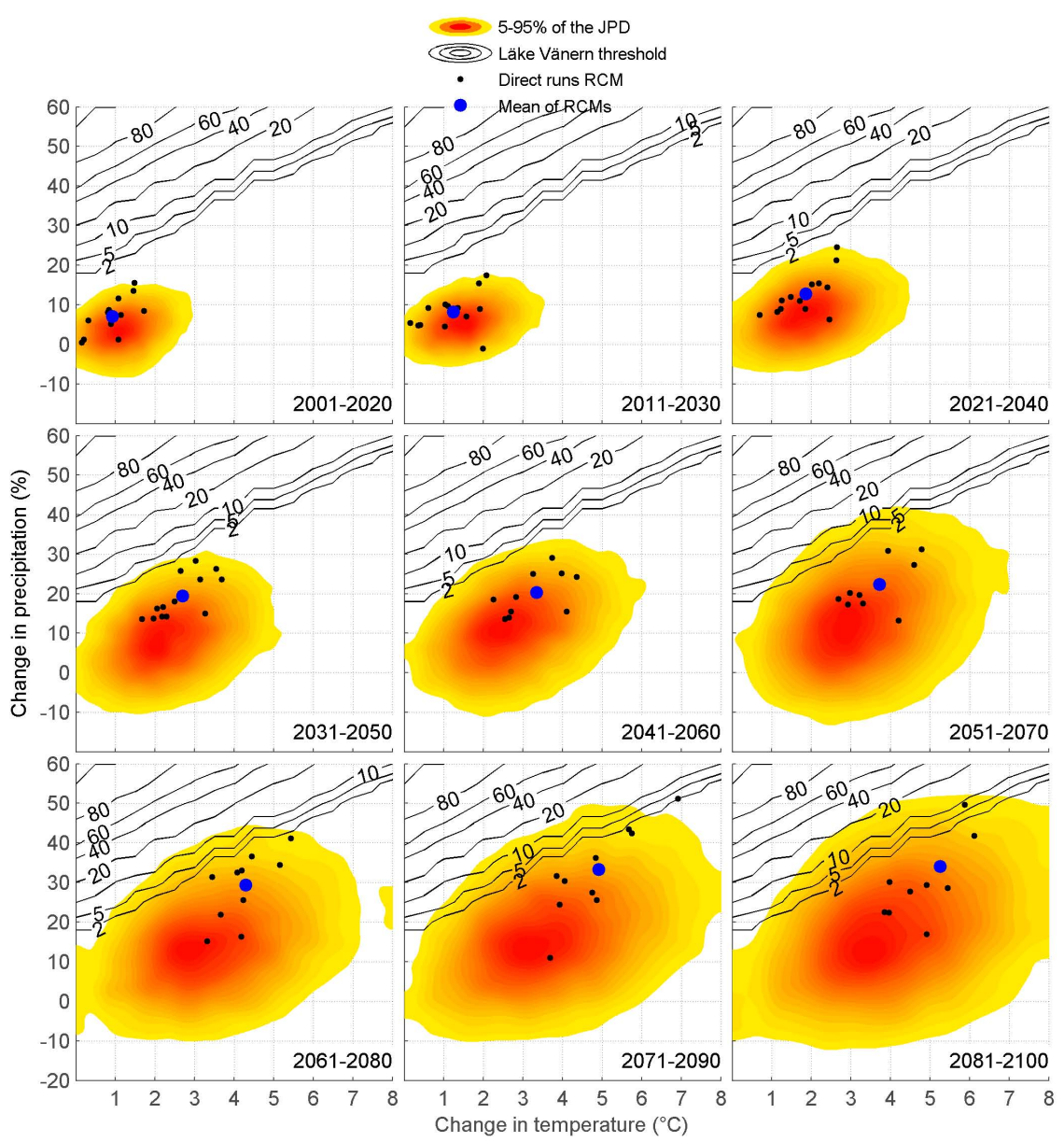

Fig. 6. Climate change results with the JPD and RCM simulations overlaid on the response surface for the threshold for Lake Vänern over the winter period (September-February). The JPD distributions were cut at the 5 and 95 percentiles to show only the robust simulations. The RCM simulations are denoted by the dots, and the larger dot is the mean of the RCM simulations.

\subsection{Response surfaces}

\subsubsection{Lake Vänern basin}

The seasonal change in temperature and precipitation from the JPD suggested a relatively constant change in the temperature throughout the year, but a seasonal change in precipitation for the Lake Vänern basin (Fig. 2), and the response surfaces resulting from this type of perturbation, were used for Lake Vänern. The modelled response surface for the 100-day outflow threshold for Lake Vänern basin is shown in Fig. 3. The results for the annual perturbations of precipitation and temperature were quite similar to the seasonal perturbations, so these are not shown here. The response surface is more sensitive to changes in precipitation than temperature, which is not surprising since the event is flood related. However, increased temperature, which leads to increased evapotranspiration and therefore drier antecedent conditions in the soil, does affect the flood risk. It should be noted here that the underlying runoff series (1961-1990) does not contain the observed event of 2000-2001 which has been estimated as a 200-yr event.

\subsubsection{Lake Mälaren basin}

As for Lake Vänern, the temperature change from the JPD was best expressed as a relatively constant change, and the seasonal change in precipitation showed a decrease in summer and an increase in all other seasons. The response surfaces for the Lake Mälaren basin were more sensitive to representation of seasonal perturbations than those for Lake Vänern, both for the selected threshold and the change in annual runoff (Fig. 4). Also, the threshold for Lake Mälaren was more sensitive to changes in temperature than precipitation within the given ranges of changes in temperature and precipitation. Changes of annual runoff were less when seasonal perturbations were used (Fig. 4a). Although there is already risk for low water levels in today's climate, this increases considerably with increasing temperature (Fig. 4b) 


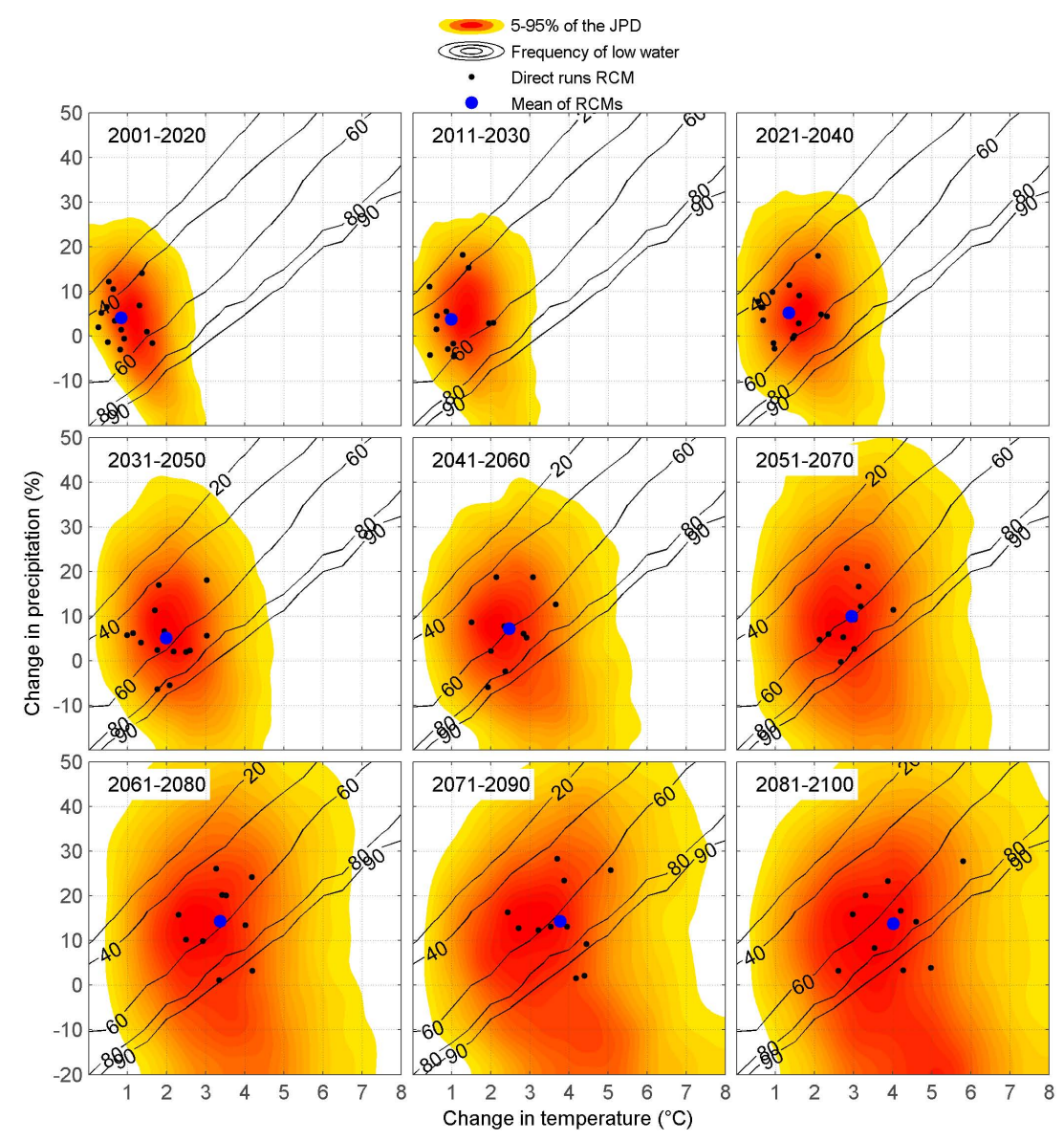

Fig. 7. Climate change results overlaid on the response surface for Lake Mälaren for the low water threshold for the summer period (MarchAugust). The JPD distribution is cut at the 5 and 95 percentiles to show only the robust simulations. The RCM simulations are denoted by the dots, and the larger dot is the mean of the RCM simulations.

According to the prior estimated seasonal climate change effects in Sweden, precipitation was projected to decrease during summer months for all basins (Fig. 2). However, the threshold for Lake Mälaren was selected as minimum water level during summer, making this basin particularly sensitive to how spring-summer precipitation changes are represented in response surfaces.

\subsubsection{Lule River}

This basin showed very little difference in runoff response between seasonal or annual perturbations (Fig. 5). More important is that the response surfaces indicate a dramatic shift in the timing of the spring flood, shown as an increase in winter and spring runoff, and a decrease in summer runoff. The main driver of this change is the temperature perturbations. The Lule River response surfaces reflect the specific response characteristics of snow accumulation and melt, which is more pronounced here than in more southern basins, such as Lake Vänern.

\subsection{Future climate simulations}

Output from the JPD perturbed physics ensemble was overlaid on the response surfaces to evaluate effects of the projected SRES-A1B emissions scenario. The results from this experiment were also compared to outputs from the RCM simulations. Even though the GCMs used in the RCM simulations were somewhat different from those used for the JPD experiment, a comparison is still useful. If both approaches give similar results, it could be a sign that the climate change signal for that particular basin is fairly robust.

\subsubsection{Changes in temperature and precipitation}

The changes in precipitation and temperature over the basins follow similar patterns for Lake Vänern and Lake Mälaren, with a decrease in the summer precipitation and an increase in the winter months (Fig. 2). There is a very small seasonal signal in temperature changes, but the general pattern is an increase over all seasons. This is different from earlier GCM results for the basins which indicated a larger 


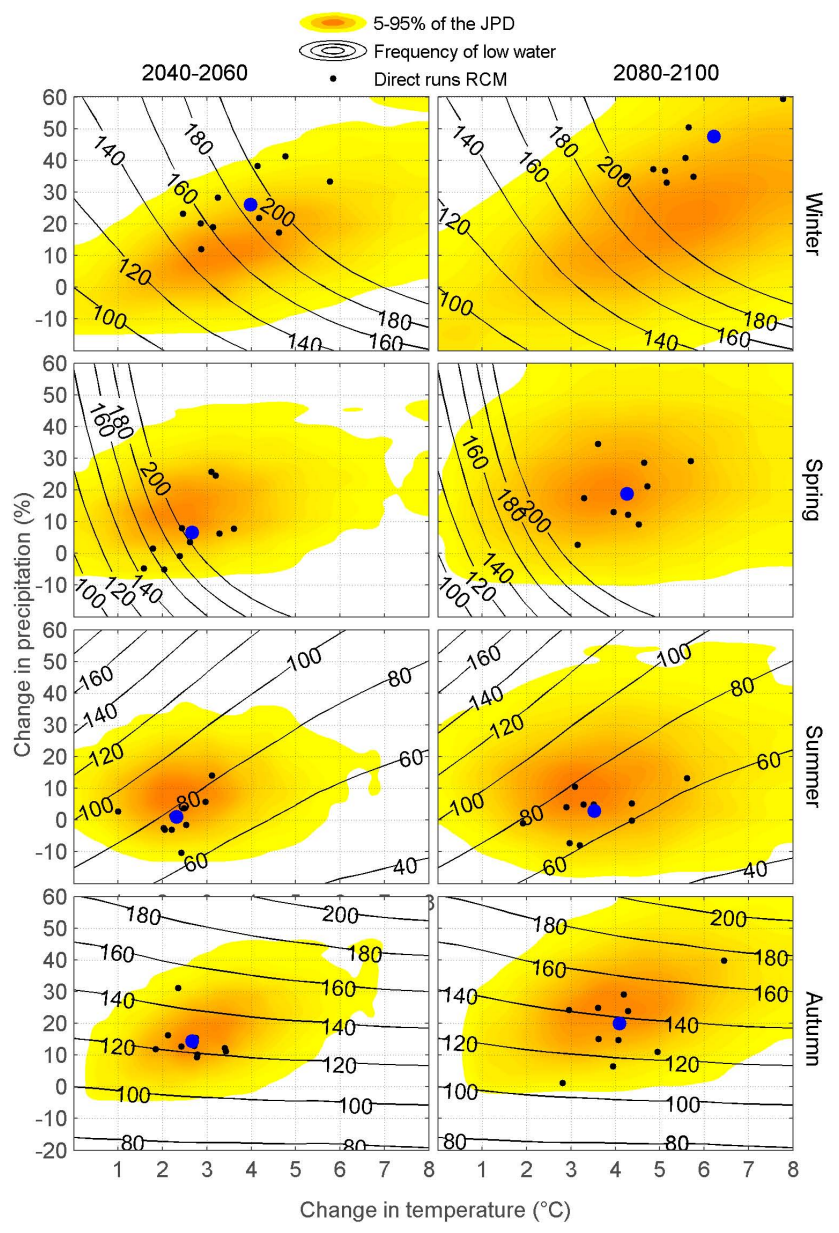

Fig. 8. Climate change results overlaid on the seasonal runoff response surfaces for the Lule River basin. The climate runs are time slices from (a) 2041-2060 and (b) 2081-2100.

temperature increase over winter months than during the summer. However, a more pronounced seasonal difference is seen for the Lule River, where the temperature increase for the winter season is much larger than other seasons.

\subsubsection{Lake Vänern basin}

The 100-day outflow response surface for Lake Vänern indicates that the risk of reaching the critical threshold does not increase in the future simulations (Fig. 6). However, the spread of the JPD increases towards the end of the century, and therefore the modelled uncertainty. The RCM simulations in general agree with the overall simulations from the JPD. However, the RCM results indicate a larger increase in precipitation than the JPD and also a larger spread between the RCMs. This spread can result from the different GCM forcings used and local effects in the different RCMs.

The fact that the chosen threshold is not frequently reached in the projections may well lie in the rarity of the event. As noted earlier, the basis of the 100-day outflow threshold lies

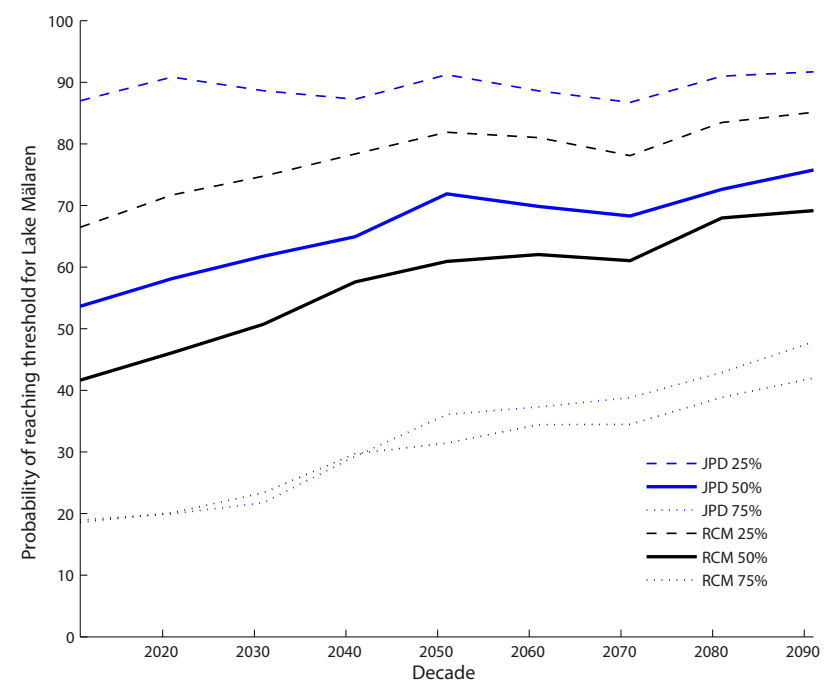

Fig. 9. Cumulative estimated probabilities of going under the low water threshold for Lake Mälaren for each decade 2010-2100. The blue lines are the estimated probabilities from the JPD simulations and the black lines from the RCM simulations. Shown are the estimated probabilities that the low water in Lake Mälaren goes under the threshold $25 \%, 50 \%$ and $75 \%$ percent of the years for each decade.

in an extremely infrequent event. It is likely that all of the models involved in this study, both climate and impact, have difficulty representing such infrequent events, both for the present climate and for the future. Such factors should be considered when choosing critical thresholds and this particular threshold may not be completely appropriate for application with the modelled data. Additional analysis is needed to investigate this. Using a top-down approach, results from Olsson et al. (2011) show a stronger tendency for increased flow to Lake Vänern, and consequently higher flood risk.

\subsubsection{Lake Mälaren basin}

For Lake Mälaren, the situation is shown to be more severe in the future (Fig. 7). Reaching or exceeding the low water threshold as defined above would occur more frequently in the future, according to both the JPD and RCM simulations. This indicates the importance of securing future water availability, transport and water quality for a region projected to substantially grow in the future. There is some tendency for the HBV Model to overestimate evaporation with large temperature increases, so the results for the low-water simulations are subject to more uncertainty than for the high flows. The RCM results agree with those of the JPD simulations rather well, although the relative spread is larger, as for Lake Vänern. Parameter uncertainty for the HBV model was not included in this study, and this may be most important regarding Lake Mälaren since increase of evapotranspiration will affect the low water levels. Also, stationarity is 


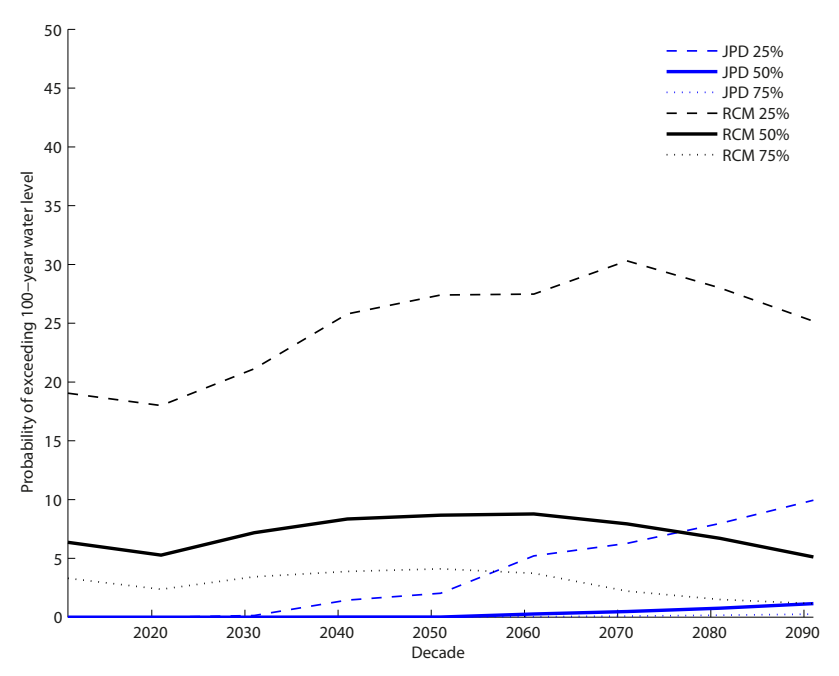

Fig. 10. Cumulative probabilities of exceeding the high water level threshold for Lake Vänern for each decade 2010-2100. The blue lines are the estimated probabilities from the JPD simulations and the black lines from the RCM simulations. Shown are the estimated probabilities that the threshold is exceeded $25 \%, 50 \%$ and $75 \%$ percent of the years for each decade. Observe that the maximum probability exceedance on the Y-axis is $50 \%$.

assumed, and it is likely that both changes in land-use and climate could lead to situations that are not covered in this study.

\subsubsection{Lule River basin}

The results for the Lule River (Fig. 8) show increases of runoff for all seasons except summer (JJA). The change in seasonal flow is apparent already by 2050 (Fig. 8, left column), and the pattern is manifested towards the end of the century (Fig. 8, right column). As historical peak flows occur during JJA, this indicates that the future risk of flooding does not increase although precipitation increases. The reason for this is mainly that the increasing temperature leads to a shift in the seasonal patterns of runoff due to changes in snow dynamics. These results also indicate useful trends for the hydropower industry, as they show increases in runoff during winter months that could potentially be used for additional power generation. Differences between the JPD and RCM simulation results are more pronounced for the Lule River in winter than the other seasons.

\subsubsection{JPD versus RCM simulations}

Differences in results from JPD versus the RCM simulations are apparent in Figs. 6-10. The general pattern is that the RCMs indicate a wider spread than for JPD simulations in the beginning of the century, but the range of uncertainty increases in the JPD towards the end of the century. This could originate in the fact that the RCMs are run at a higher resolution, including more of the local variability, therefore increasing the variability of the results. Secondly, the RCM simulations were based on different driving GCMs and they reflect to some extent a range of different GCM outcomes. A third aspect of difference is that the RCM simulations were bias-corrected to be more similar to observed distributions of precipitation and temperature. Despite all these differences, the RCMs are almost never outside the range of the JPD, indicating the usefulness of performing uncertainty assessments of the climate runs. This also provides useful information that the models are showing consistent signals. Whether this can be interpreted as a more "robust" signal of the future climate change or not is questionable, since all models could be equally wrong, but it does provide stakeholders with a clearer picture of what the science is suggesting about climate change impacts.

\subsection{Estimating future probabilities of exceeding thresholds}

The probability of exceeding the response surface thresholds can be estimated from the JPD experiment as well as from the RCM simulations. The probabilities from the JPD were estimated by calculating the frequencies of simulations exceeding the threshold for each decade, whereas the estimated joint distribution from the bivariate kernel density estimator for the RCM runs were used to assess the probabilities of threshold exceedance. Cumulative probabilities that the 25, 50 and 75 percentiles of the Lake Mälaren low water threshold and the Lake Vänern 100-yr water level threshold are exceeded were estimated and plotted against time (Figs. 9 and 10). For example, in 2020 the probability of reaching the low water level in Lake Mälaren $50 \%$ of the time is about $56 \%$ according to the JPD. The RCM simulations indicate a probability of about $45 \%$ for the same threshold. Although there is some discrepancy between these two sets of results, the increasing trends in Fig. 9 are similar for both JPD and for RCM results. The figure also shows the large spread in the results, where some simulations, both from the JPD and the RCMs, indicate a less severe condition in the future. The results for Lake Mälaren are not so surprising, since summer temperature is very important for the evapotranspiration and low water, and the change for RCM and JPD are similar for the summer months (Fig. 7). The mean of the RCM runs are in general concurring with the JPD plot.

The discrepancy between RCM and JPD is larger for winter precipitation, which is illustrated in the response surface for Lake Vänern (Fig. 6). This results in large differences between the RCM estimated probabilities of exceedance compared with the JPD (Fig. 10). Similar results were obtained for both the 100-day outflow and the 100-yr water level thresholds, but as the results were even more pronounced for the latter, it was chosen to illustrate this point. The RCMs indicate an increase in risk of reaching dangerous water levels with a peak around 2050 for the 50 percentile, and then the 
risk declines. The JPD shows a different development, with a low risk up until 2050, and then a constant increase. The discrepancy between the RCMs and GCM-based JPD can likely be attributed to the better description of precipitation in the RCMs, as well as the bias correction on these simulations. The decline in risk towards the end of the century can partly be explained by the increase in temperature, and therefore a higher evapotranspiration that somewhat decreases the risk of reaching the threshold.

\section{Conclusions}

This study had two main objectives: (1) to assess how climate change would affect three different basins in Sweden, and (2) to evaluate response surfaces as a means to analyse and visualise probabilistic climate scenarios. The main conclusions from the first objective are that:

- Undesirable low water levels for Lake Mälaren are likely to be more common in a future climate, leading to potential problems for water quality and transport.

- High water levels in Lake Vänern may increase in the future, but the response surfaces do not agree on the magnitude and timing of this increase

- Lule River is very likely to have a shift towards more winter and spring runoff, whereas the summer runoff will decrease.

The main conclusions regarding the second objective are:

- Response surfaces provide a visualisation tool for expressing probabilistic hydrological change.

- Probabilistic trends for future change in hazards or potential can be shown and evaluated.

- Uncertainties (robustness) because of differences (similarities) between RCM and GCM projections of future changes can be assessed.

Response surfaces are an effective way of visualising local climate impact modelling. An advantage is the ability to calculate the joint probabilities of a multitude of future climate scenarios in terms of the risk of reaching a predetermined threshold. However, good understanding of the local conditions is required in finding appropriate thresholds for a specific drainage area, since the conditions vary from basin to basin. Stakeholders should better appreciate the risk assessment if the threshold is a well-known and well-defined situation, rather than merely a change in the mean climate. However, choice of thresholds should also take into consideration potential deficiencies in the models for adequately representing the threshold conditions. Use of response surfaces showing seasonal runoff change in relation to today's conditions also offers a simple way to communicate climate change effects to specific sectors, such as hydropower.
Acknowledgements. Many of the climate model projections came from the ENSEMBLES Project, funded by the European Commission's 6th Framework Programme through contract GOCE-CT-2003-505539). Others were provided by the Rossby Centre at SMHI. The work was funded in part by ENSEMBLES, and the SAWA and CPA projects under the EU Interreg IVB North Sea Region Programme. Fredrik Wetterhall was partly funded by a NERC FREE project (Grant No. NE/E002242/1). We also acknowledge the anonymous reviewer for helpful comments.

Edited by: J. E. Olesen

Reviewed by: two anonymous referees

\section{References}

Andréasson, J., Bergström, S., Carlsson, B., Graham, L. P., and Lindström, G.: Hydrological change - climate change impact simulations for Sweden, Ambio, 33, 228-234, 2004.

Arheimer, B. and Brandt, M.: Modelling nitrogen transport and retention in the catchments of southern Sweden, Ambio, 27, 471480, 1998.

Arheimer, B., Andréasson, J., Fogelberg, S., Johnsson, H., Pers, C. B., and Persson, K.: Climate change impact on water quality: Model results from southern Sweden, Ambio, 34, 559-566, 2005.

Bergström, S., Carlsson, B., Gardelin, M., Lindström, G., Pettersson, A., and Rummukainen, M.: Climate change impacts on runoff in Sweden - assessments by global climate models, dynamical downscaling and hydrological modelling, Clim. Res., 16, 101-112, 2001.

Beven, K.: I believe in climate change but how precautionary do we need to be in planning for the future?, Hydrol. Process., 25, 1517-1520, 2011.

Botev, Z. I., Grotowski, J. F., and Kroese, D. P.: Kernel density estimation via diffusion, Ann. Stat., 38, 2916-2957, 2010.

Carter, T. and Fronzek, S.: Applying probabilistic climate projections to impact models, ENSEMBLES RT 6/WP 6.2 meeting, Exeter, UK, 6-8 June 2005.

Christensen, J. H., Christensen, O. B., Lopez P., van Meijgaard, E., and Botzet, M.: The HIRHAM4 Regional Atmospheric Climate Model, DMI Scientific Report 96-4, 1996.

Christensen, J. H., Carter, T. R., Rummukainen, M., and Amanatidis, G.: Evaluating the performance and utility of regional climate models: the PRUDENCE Project, Clim. Change, 81, 1-6, 2007.

Déqué, M.: Frequency of precipitation and temperature extremes over France in an anthropogenic scenario: Model results and statistical correction according to observed values, Glob. Planet. Change, 57, 16-26, 2007.

Fowler, H. J., Blenkinsop, S., and Tebaldi, C.: Linking climate change modelling to impacts studies: recent advances in downscaling techniques for hydrological modelling, Int. J. Climatol., 27(12), 1547-1578, 2007.

Graham, L. P., Andréasson, J., and Carlsson, B.: Assessing climate change impacts on hydrology from an ensemble of regional climate models, model scales and linking methods - a case study on the Lule River Basin, Clim. Change, 81, 293-307, 2007a.

Graham, L. P., Hagemann, S., Jaun, S,. and Beniston, M.: On interpreting hydrological change from regional climate models, Clim. 
Change, 81, 97-122, 2007b.

Gibelin, A. L. and Déqué, M.: Anthropogenic climate change over the Mediterranean region simulated by a global variable resolution model, Clim. Dynam., 20, 327-339, 2003.

Harris, G. R., Collins, M., Sexton, D. M. H., Murphy, J. M., and Booth, B. B. B.: Probabilistic projections for 21 st century European climate, Nat. Hazards Earth Syst. Sci., 10, 2009-2020, doi:10.5194/nhess-10-2009-2010, 2010.

Haugen, J. E. and Haakenstad, H.: Validation of HIRHAM version 2 with $50 \mathrm{~km}$ and $25 \mathrm{~km}$ resolution, RegClim General Technical Report No. 9, 159-173, 2006.

IPCC: Climate Change 2007: The Physical Science Basis. Contribution of Working Group I to the Fourth Assessment Report of the Intergovernmental Panel on Climate Change, edited by: Solomon, S., Qin, D., Manning, M., Chen, Z., Marquis, M., Averyt, K. B., Tignor, M., and Miller, H. L., Cambridge University Press, Cambridge, UK and New York, USA, 996 pp., 2007.

Jacob, D., Andrae, U., Elgered, G., Fortelius, C., Graham, L. P., Jackson, S. D., Karstens, U., Koepken, C., Lindau, R., Podzun, R., Rockel, B., Rubel, F., Sass, H. B., Smith, R. N. D., Hurk, B. J. J. M. Van den, and Yang, X.: A Comprehensive Model Intercomparison Study Investigating the Water Budget during the BALTEX-PIDCAP Period, Meteorol. Atmos. Phys., 77(1-4), 19-43, 2001.

Johansson, B. and Chen, D.: The influence of wind and topography on precipitation distribution in Sweden: Statistical analysis and modelling, Int. J. Climatol., 23, 1523-1535, 2003.

Jones, C. G., Willén, U., Ullerstig, A., and Hansson, U.: The Rossby Centre regional atmospheric climate model part I: model climatology and performance for the present climate over Europe, Ambio, 33, 199-210, 2004.

Jones, R. G., Murphy, J. M., and Noguer, M.: Simulation of climatechange over Europe using a nested regional-climate model, Part I: Assessment of control climate, including sensitivity to location of lateral boundaries, Q. J. Roy. Meteor. Soc., 121, 1413-1449, 1995.

Jones, R. N.: An environmental risk assessment/management framework for climate change impact assessments, Nat. Hazards, 23, 197-230, 2001.
Kjellström, E., Bärring, L., Gollvik, S., Hansson, U., Jones, C., Samuelsson, P., Rummukainen, M., Ullerstig, A., Willén, U., and Wyser, K.: A 140-year simulation of European climate with the new version of the Rossby Centre regional atmospheric climate model (RCA3), SMHI, Sweden, Reports Meteorology and Climatology, 108, 54 pp., 2005.

Lindström, G., Johansson, B., Persson, M., Gardelin, M., and Bergström, S.: Development and test of the distributed HBV-96 model, J. Hydrol., 201, 272-288, 1997.

Meijgaard, E. van, Ulft, L. H. van, Berg, W. J. van de, Bosveld, F. C., Hurk, B. J. J. M. van den, Lenderink, G., and Siebesma, A. P.: The KNMI regional atmospheric climate model RACMO, version 2.1., KNMI Technical Report 302, 43 pp., 2008.

Olsson, J., Andréasson, J., Graham, L. P., Rosberg, J., and Yang, W.: Hydrological climate change impacts on inflows to Lake Vänern, Sweden: An ensemble approach, Tellus A, 63, 126-137, 2011.

SOU 2007:60 (Swedish Government Commission Report): Sweden facing climate change - threats and opportunities, The Commission on Climate and Vulnerability, Swedish Government Official Reports, 679 pp., 2007.

van der Linden, P. and Mitchell, J. F. B.: ENSEMBLES: Climate Change and its Impacts: Summary of research and results from the ENSEMBLES project, Met Office Hadley Centre, FitzRoy Road, Exeter EX1 3PB, UK, 160 pp., 2009.

Vehviläinen, B. and Huttunen, M.: Climate change and water resources in Finland, Boreal. Environ. Res., 2, 3-18, 1997.

Wilby, R. L.: Evaluating climate model outputs for hydrological applications, Hydrolog. Sci. J., 55, 1090-1093, 2010.

Wilby, R. L. and Harris, I.: A framework for assessing uncertainties in climate change impacts: Low-flow scenarios for the River Thames, UK, Water Resour. Res., 42, W02419, doi:10.1029/2005WR004065, 2006.

Yang, W., Andréasson, J., Graham, L. P., Olsson, J., Rosberg, J., and Wetterhall, F.: Distribution-based scaling to improve usability of regional climate model projections for hydrological climate change impacts studies, Hydrol. Res., 41, 211-229, 2010. 